\title{
A seasonal agricultural drought forecast system for food-insecure regions of East Africa
}

\author{
S. Shukla ${ }^{1,2}$, A. McNally ${ }^{1,4,5}$, G. Husak ${ }^{1}$, and C. Funk ${ }^{3,1}$ \\ ${ }^{1}$ Climate Hazards Group, Department of Geography, University of California, Santa Barbara, CA, USA \\ ${ }^{2}$ University Corporation for Atmospheric Research, Boulder, CO, USA \\ ${ }^{3}$ U.S. Geological Survey, Earth Resources Observation and Science Center, Sioux Falls, USA \\ ${ }^{4}$ Earth System Science Interdisciplinary Center, University of Maryland, College Park, MD, USA \\ ${ }^{5}$ Hydrological Sciences Laboratory, NASA Goddard Space Flight Center, Greenbelt, MD, USA \\ Correspondence to: S. Shukla (shrad@geog.ucsb.edu)
}

Received: 21 February 2014 - Published in Hydrol. Earth Syst. Sci. Discuss.: 14 March 2014

Revised: 30 July 2014 - Accepted: 21 August 2014 - Published: 2 October 2014

\begin{abstract}
The increasing food and water demands of East Africa's growing population are stressing the region's inconsistent water resources and rain-fed agriculture. More accurate seasonal agricultural drought forecasts for this region can inform better water and agropastoral management decisions, support optimal allocation of the region's water resources, and mitigate socioeconomic losses incurred by droughts and floods. Here we describe the development and implementation of a seasonal agricultural drought forecast system for East Africa (EA) that provides decision support for the Famine Early Warning Systems Network's (FEWS NET) science team. We evaluate this forecast system for a region of equatorial EA $\left(2^{\circ} \mathrm{S}-8^{\circ} \mathrm{N}, 36-46^{\circ} \mathrm{E}\right)$ for the MarchApril-May (MAM) growing season. This domain encompasses one of the most food-insecure, climatically variable, and socioeconomically vulnerable regions in EA, and potentially the world; this region has experienced famine as recently as 2011 .

To produce an "agricultural outlook", our forecast system simulates soil moisture (SM) scenarios using the Variable Infiltration Capacity (VIC) hydrologic model forced with climate scenarios describing the upcoming season. First, we forced the VIC model with high-quality atmospheric observations to produce baseline soil moisture (SM) estimates (here after referred as SM a posteriori estimates). These compared favorably (correlation $=0.75$ ) with the water requirement satisfaction index (WRSI), an index that the FEWS NET uses to estimate crop yields. Next, we evaluated the SM forecasts generated by this system on 5 March and 5 April
\end{abstract}

of each year between 1993 and 2012 by comparing them with the corresponding SM a posteriori estimates. We found that initializing SM forecasts with start-of-season (SOS) (5 March) SM conditions resulted in useful SM forecast skill ( $>0.5$ correlation) at 1-month and, in some cases, 3-month lead times. Similarly, when the forecast was initialized with midseason (i.e., 5 April) SM conditions, the skill of forecasting SM estimates until the end-of-season improved (correlation $>0.5$ over several grid cells). We also found these SM forecasts to be more skillful than the ones generated using the Ensemble Streamflow Prediction (ESP) method, which derives its hydrologic forecast skill solely from the knowledge of the initial hydrologic conditions. Finally, we show that, in terms of forecasting spatial patterns of SM anomalies, the skill of this agricultural drought forecast system is generally greater ( $>0.8$ correlation) during drought years (when standardized anomaly of MAM precipitation is below 0). This indicates that this system might be particularity useful for identifying drought events in this region and can support decision-making for mitigation or humanitarian assistance.

\section{Introduction}

The 2011 famine in the Horn of Africa was one of the most severe humanitarian disasters of this century. It affected more than 13 million people (Hillier, 2012) and resulted in a disastrous loss of life. According to the Food and Agriculture Organization (FAO) and Famine Early Warning Systems 
Network (FEWS NET) reports, there were between 244000 and 273000 famine-related deaths in southern and central Somalia alone (Checchi and Robinson, 2013). While the situation was most dire in this region (Mosley, 2012), the impacts spilled over the border into southeastern Ethiopia and northern Kenya. To mitigate socioeconomic losses of future drought events of this magnitude timely and adequate responses to early warnings of drought are crucial (Hillier, 2012).

FEWS NET is a program of the United States Agency for International Development (USAID) tasked with providing timely and rigorous early warning and vulnerability information on emerging and evolving food security issues. FEWS NET is active in more than 30 of the world's most foodinsecure countries including Ethiopia, Kenya, and Somalia. Each month FEWS NET's regional food analysts compile a set of agroclimatic working assumptions (i.e., hypotheses) for the upcoming season. Meanwhile FEWS NET's hydroclimate scientists review those assumptions with a deeper focus on the climate conditions and contribute to the assumptions if need be. This process requires compiling available information on soil moisture (SM), rainfall, vegetation health, sea surface temperatures (SSTs) and temperatures (land surface and air) to provide weekly-to-seasonal climate outlooks.

Thus far, the hydroclimate science team has focused on forecasting rainfall anomalies of the upcoming season, as well as real-time monitoring and attribution activities (Funk et al., 2005, 2010). Due to this attention, rainfall estimation has also experienced significant technical advances and is the premier input to assess agricultural production and available water resources (Funk et al., 2014b). While seasonal rainfall may be the most accessible indicator of yields, we argue that future attention needs to be shifted toward monitoring and forecasting of SM. Rainfall indicates meteorological drought, whereas SM in cropping zones during the growing season is a more direct indicator of agricultural drought. Furthermore, accurate SM initialization significantly contributes to the forecast skill of available moisture for up to 6 months (Koster et al., 2010; Shukla and Lettenmaier, 2011; Shukla et al., 2013). Due to the shortage of real-time-observed SM measurements, estimates computed using hydrologic models are among the best indicator of antecedent SM conditions and agricultural drought (Keyantash and Dracup, 2002). These same hydrologic models can be driven with climate forecasts for the upcoming season to provide SM forecasts. This additional step of using forecast rainfall and other meteorological variables to provide a seasonal outlook for plant available water provides a more nuanced and accurate assessment of agricultural drought conditions than rainfall forecasts alone. We show here that the combination of rainfall observations and forecasts produces more accurate SM predictions.

During the October-November-December growing season of 2013, the FEWS NET science team developed and implemented a seasonal agricultural drought forecast system

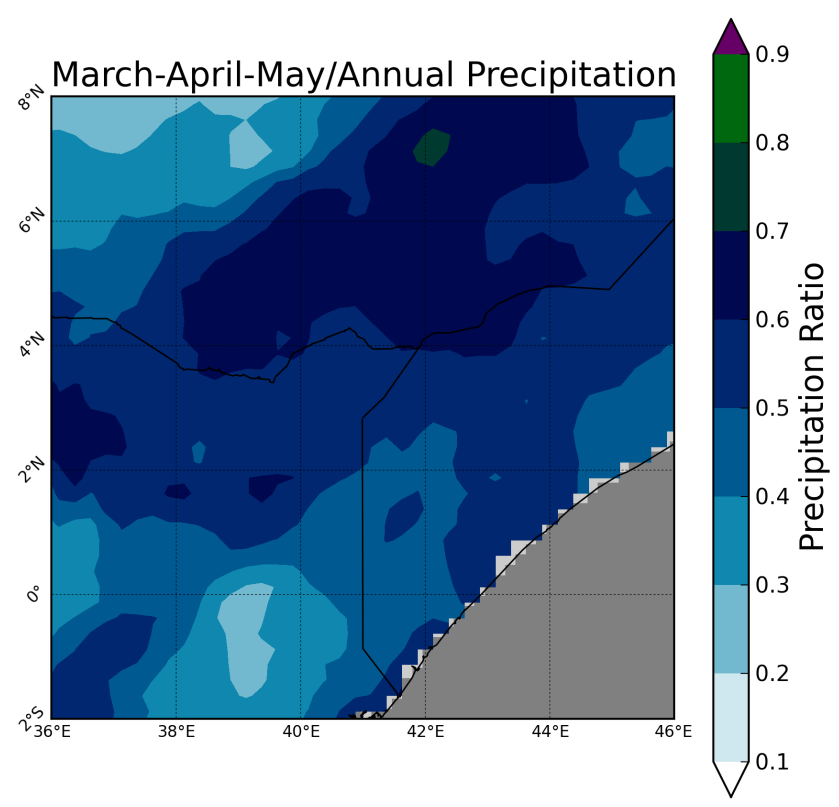

Figure 1. Ratio of MAM precipitation with the annual precipitation (calculated using CHIRPS) over the focus domain that expands over parts of Ethiopia, Kenya and Somalia. This region was the epicenter of the 2011 humanitarian disaster.

using the Variable Infiltration Capacity (VIC) hydrologic model and National Centers of Environmental Prediction's (NCEP) Climate Forecasts System Version 2 (CFSv2). This system produces SM forecasts that are used for providing agricultural drought assessment. The primary objective of this manuscript is to describe the development and evaluation of the SM forecasts generated by the seasonal drought forecast system. Although the intended domain of this system expands over the Greater Horn of Africa, we focus on the equatorial East Africa (EA) (i.e., southeastern Ethiopia, northern Kenya, and southern Ethiopia as captured in Fig. 1) as a testbed. This region is predominantly a pastoral area with some crop zones. For evaluation of this system we chose to focus on March-April-May (MAM), which is the primary growing and rainy season as shown by the ratio of MAM and annual precipitation based on the Climate Hazards Group InfraRed Precipitation with Station data (CHIRPS) data set (Funk et al., 2014b) (see Sect. 2.2) in Fig. 1.

Reliable rainfall forecasts at a seasonal scale over this region during the rainy season have proven to be a challenge (Nicholson, 2014; Owiti et al., 2008). However, retrospective analysis shows us that rainfall in the MAM season has declined in last 2 decades (Funk et al., 2008; Lyon and DeWitt, 2012; Williams and Funk, 2011). Although the primary causes of this decline has been a matter of debate (Hoell and Funk, 2013a; Lyon and DeWitt, 2012; Tierney et al., 2013), it seems likely that both anthropogenic warming and decadal variability have contributed to more frequent droughts, but in ways that may be making rainfall more predictable (Funk 


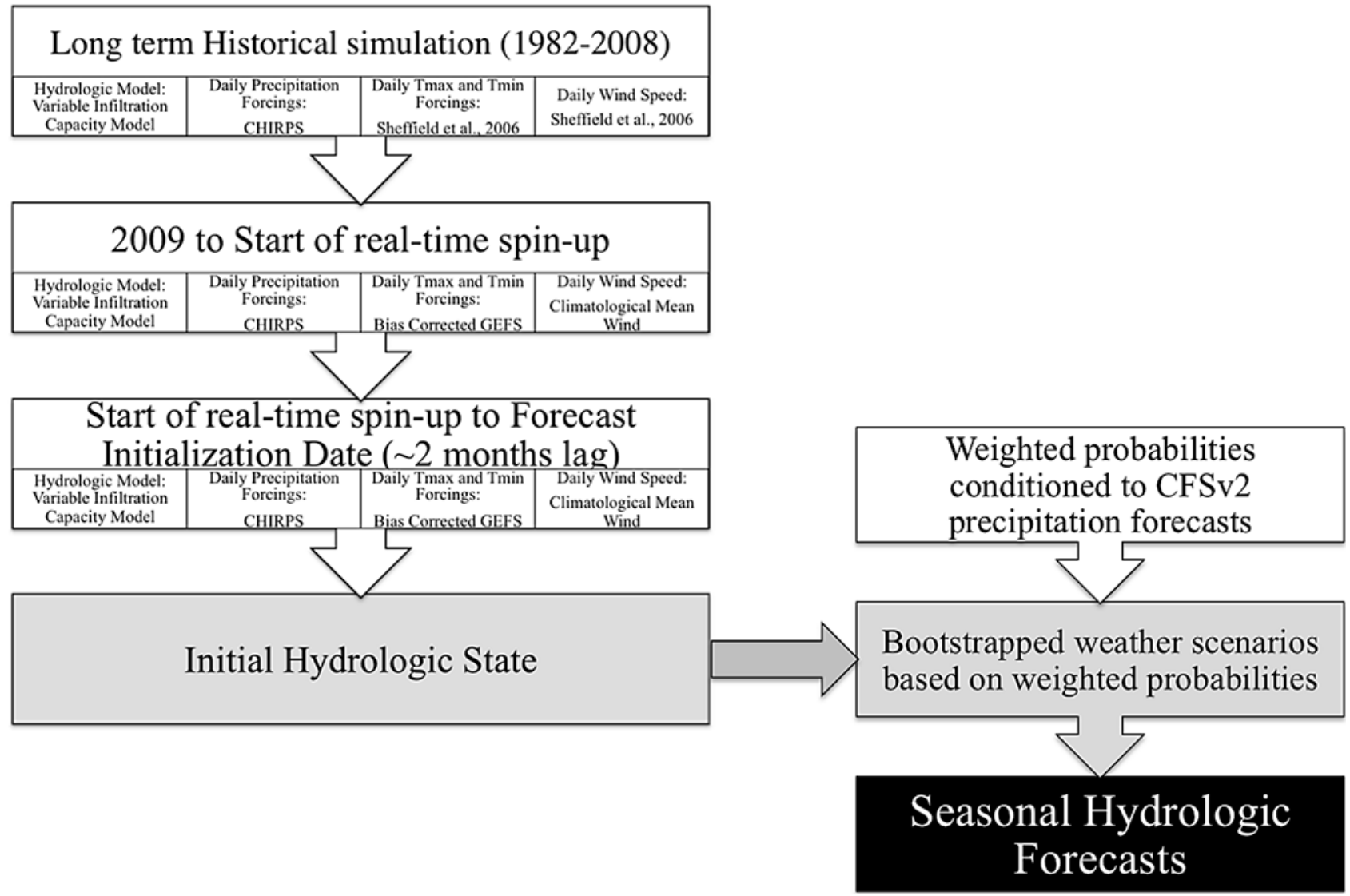

Figure 2. Schematic diagram summarizing the approach, data, and models used for the development and implementation of the current version of the seasonal agricultural drought forecast system.

et al., 2013, 2014a). In the future, the MAM season will continue to be prone to drought events and continue to pose challenges for water and drought management, given increases in population and water demands as well as degradation of land in the past few decades (Pricope et al., 2013). These facts support a need to improve and develop tools to assist decision-makers.

In the remainder of this manuscript we describe the approach and data used to implement the agricultural drought forecasts system, its evaluation, and future directions.

\subsection{Approach and data}

This section describes the approach undertaken to develop the seasonal agricultural drought forecast system. Our approach is similar to other experimental/operational seasonal hydrologic and drought forecast systems including the NCEP's multimodal drought monitoring system (http://www.emc.ncep.noaa.gov/mmb/nldas/drought/), the Climate Prediction Center's land surface monitoring and prediction system (http://www.cpc.ncep.noaa.gov/products/ Soilmst_Monitoring/US/Soilmst/Soilmst.shtml), as well as Princeton University's Africa Flood and Drought Monitor
(http://stream.princeton.edu/AWCM/WEBPAGE/index.php) (Sheffield et al., 2014) and the contiguous United States (CONUS) seasonal drought forecasting system (http://hydrology.princeton.edu/forecast/current.php) (Yuan et al., 2013b).

We used the same model parameters and temperature and wind forcings as these systems; however, we used different precipitation and a different approach for generating seasonal climate scenarios. More specifically, the CHIRPS rainfall data set blends in more station data than other products and uses a high-resolution background climatology, providing better estimates of precipitation means and variations, resulting in a better hydrologic state. The seasonal climate scenarios are based on a statistical-dynamical downscaling approach that leverages the strengths of global forecast systems. A schematic diagram shown in Fig. 2 summarizes our approach and lists all the data and models used to implement this system.

In following sections we describe in detail the hydrology model (Sect. 2.1), observed atmospheric forcings (Sect. 2.2), and the methodology adopted to build seasonal climate scenarios (Sect. 2.3) and generate seasonal forecasts of SM (Sect. 2.4). 


\subsection{Hydrologic model and parameters}

For this analysis we used the VIC model, which is a semidistributed macroscale hydrology model. The VIC model has been widely used at a global scale and has been demonstrated to accurately capture the hydrology of different regimes (Nijssen et al., 1997, 2001a, b; Maurer et al., 2002; Adam et al., 2007).

The VIC model parameterizes major surface, subsurface, and land-atmosphere hydrometeorological processes (Liang et al., 1994, 1996; Nijssen et al., 1997) and represents the influence of subgrid spatial heterogeneity (in SM, elevation, and vegetation) on runoff generation. The VIC model uses the University of Maryland land cover classification system to assign different vegetation types (and bare soil) to each grid cell. Actual evapotranspiration in the VIC model is calculated using the Penman-Monteith equation. Total actual evapotranspiration is the sum of transpiration and canopy and bare soil evaporation, weighted by the land cover fraction within each grid cell. The soil profile (i.e., depth) in the VIC model is partitioned into three layers. The first layer has a fixed depth of $10 \mathrm{~cm}$ and responds quickly to changes in surface conditions and precipitation, while the lower layers characterize slower, seasonal SM behavior. Moisture transfers between the first and second, and second and third soil layers are governed by gravity drainage, with diffusion from the second to the upper layer allowed in unsaturated conditions (Liang et al., 1996). Baseflow is a nonlinear function of the moisture content of the third soil layer (Todini, 1996).

The soil and vegetation parameters used for this study were originally developed for Princeton's Africa Flood and Drought Monitor (http://hydrology.princeton. edu/ nchaney/ADMML/), documented in Sheffield et al. (2014) and Chaney et al. (2014). For a complete list of the soil parameters used by the VIC model see http://www.hydro.washington.edu/Lettenmaier/Models/ VIC/Documentation/SoilParam.shtml. We briefly describe their origin and sources here for the benefit of the reader. Soil texture and bulk density were from Batjes (1997) and the rest of the soil parameters were from Cosby et al. (1984). In order to insure that the VIC model yields reasonable water balance, the soil parameters were calibrated, following the method of Troy et al. (2008), against runoff fields derived by Global Runoff Data Center gauges in Africa. Troy et al. (2008) demonstrated that this approach is sufficiently accurate, computationally efficient, and results in reasonable soil parameters for ungauged basins, which makes it particularity attractive for a data sparse region such as Africa. Vegetation parameters were taken from Nijssen et al. (2001b), where each vegetation type has specific root length, minimum stomatal resistance, architectural resistance, roughness length, and displacement length. Leaf area index (LAI) and albedo vary monthly. Monthly LAI values used in this study were derived from Myneni et al. (1997).

\subsection{Observed atmospheric forcings}

This project used the CHIRPS rainfall product (Funk et al., 2014b), which is available from 1981 to near present. This data set was developed and is updated at near-real time by the United States Geological Survey (USGS) in collaboration with the Climate Hazards Group of the Department of Geography at the University of California, Santa Barbara. CHIRPS is generated by blending together three different data sets: (1) global $0.05^{\circ}$ precipitation climatology, (2) time varying grids of satellite-based and climate model precipitation estimates, and (3) in situ precipitation observations. This data set has been compared with other global precipitation data sets such as the Global Precipitation Climatology Project (GPCP), and has a high level agreement in our area of interest.

Other meteorological inputs include maximum and minimum daily temperature (Tmax and Tmin) and wind speed. From 1982 to 2008 we used the data described in Chaney et al. (2014) and Sheffield et al. (2006, 2014). From 2009 to present we used Global Ensembles Forecast System (GEFS) (Hamill et al., 2013) temperature (daily Tmax and Tmin) analysis fields (accessed at http://www.esrl.noaa.gov/ $\mathrm{psd} /$ forecasts/reforecast2/download.html). For a continuous record, we bias-corrected these data relative to the previous time period using a quantile-quantile mapping approach for the overlapping climatological period of both data sets (i.e., 1985-2008). For the wind speed post-2009 we used the climatological monthly mean of wind speed data over 1982 2008. Livneh et al. (2013) demonstrated that using the climatological mean value of wind speed has minimal impact on simulated SM.

\subsection{Seasonal climate scenarios}

In order to generate SM forecasts with the VIC model, we needed scenarios of gridded daily precipitation and temperature for the upcoming season. The conventional approach is to downscale (both spatially and temporally) seasonal climate forecasts generated by dynamical models (Wood et al., 2002; Yuan et al., 2013b). However, dynamical precipitation forecasts for EA have very limited forecast skill $(r<0.3)$, especially during the main boreal spring growing season (Yuan et al., 2013b). Instead, we generated seasonal-scale climate scenarios by using the hybrid dynamical-statistical downscaling approach described here.

Our novel approach uses an ensemble of the 1993-2012 CFSv2 MAM seasonal precipitation forecasts over IndoPacific ocean region to generate climate scenarios over the EA domain. We used the CFSv2 forecasts over the IndoPacific domain because (1) there is a strong teleconnection between precipitation over Indo-Pacific region and EA rainfall during the MAM season and (2) dynamic forecast models have higher skill of over the Indo-Pacific ocean region than over terrestrial regions of EA. We limited our period of 


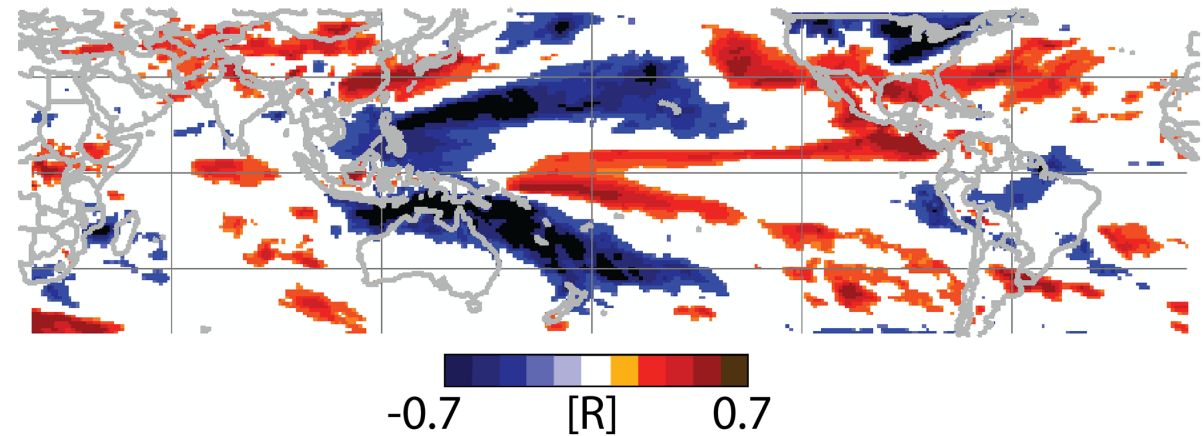

Figure 3. Spatial pattern of correlation between CFSv2 precipitation forecasts for the MAM season (initialized in February) and observed MAM rainfall (CHIRPS) in the focus domain. Correlation values have been masked for significance (values $r<|0.35|$ have been screened).

analysis for both generating climate scenarios and SM forecasts to 1993-2012 based on Funk et al. (2013), which reported that the teleconnection between MAM rainfall over the EA region (Fig. 1) and Indo-Pacific SST has been the strongest since 1993. This increase in sensitivity can partially can be attributed to the co-occurrence of La Niña events with a strong west Pacific gradient (WPG) (Hoell and Funk, 2013b). Funk et al. (2014a) revisits the empirical relationship between EA rainfall and the WPG; that heuristic paper supports the more rigorous analysis provided here.

In brief, our approach of generating seasonal climate scenarios involved first estimating the similarity between the target year precipitation forecasts and climatological years (i.e., 1993-2012, except the target years). Next, based on the similarity, we generated weights to guide a simple bootstrapping process of selection of atmospheric forcings (precipitation, temperature maximum, temperature minimum, and wind speed) from the climatological years (i.e., 1993-2012 except the target year) to generate scenarios of daily weather patterns for the target season (i.e., seasonal climate scenarios). The specific steps undertaken to generate seasonal climate scenarios are as follows.

\section{(a) Estimating weights}

1. We first calculate the correlation between the standardized anomaly of MAM observed rainfall (CHIRPS) time series averaged for the EA study region (Fig. 1) and the standardized anomaly of CFSv2 precipitation forecasts at each grid cell over the entire globe. The period of 1982-2012 is used to standardize both data sets and the correlation is calculated over 1993-2012. Areas of highest correlation $([r]>0.35)$, within the domain shown in Fig. 3 (hereafter refereed as analog domain), are used to calculate similarities between the target year and hindcast years (1993-2012) as described in steps 2 and 3.
2. We then multiply the standardized anomaly of CFSv2 forecasts of all hindcast years (1993-2012) over the analog domain by the absolute value of the correlation values (as discussed in step 1). Using the absolute correlation value allows us to put less weight on, or effectively discard, the CFSv2 forecasts for those grid cells in the analog domain that demonstrate little correlation (negative or positive) with MAM rainfall in the EA study region.

3. Next, we estimate the first principal component of correlation-scaled CFSv2 precipitation forecasts (as in step 2) and regress that against the observed MAM precipitation of the EA domain. This results in hindcast estimates (over 1993-2012) of MAM precipitation over the EA region. We then calculate the distance (i.e., squared difference) between hindcast estimates for any given target year CFSv2 forecasts with the observed precipitation of all hindcast years (1993-2012), except the target year itself. The inverse of these distances are used to produce the final weights for sampling daily seasonal climate scenarios for a given target year as described in steps 4-6.

4. The final weights for sampling daily scenarios are then generated using the inverse of distances as in step 4, referred to as " $W_{\mathrm{i}}$ " and a set of equiprobable climatological weights (i.e., $1 /$ number of years) " $W_{\text {clim }}$ ". The blending of weights to generate final weights is done based on skill "s" of hindcast estimates of precipitation (i.e., the correlation between the hindcast estimates as mentioned in step 3 and observed precipitation) as shown in Eq. (1):

$W_{\mathrm{f}}=s W_{\mathrm{i}}+(1-s) W_{\mathrm{clim}}$.

Hence in the case of $s=0$ for any given season, our approach will simply yield $W_{\mathrm{f}}=W_{\text {clim }}$, resulting in climatological forecasts, whereas the higher the skill "s", the more $W_{\mathrm{f}}$ will be closer to $W_{\mathrm{i}}$. 
This weighting scheme allows us to include all available years in the climatological period (consisting of each year between 1993 and 2012, except the target year), although at a reduced likelihood, for generating climate scenarios (in contrast to the "constructed analog" approach suggested by Hidalgo et al., 2008, which only relies on a few best analogs).

\section{(b) Generating daily scenarios}

5. To generate daily climate scenarios we start with the final weights $W_{\mathrm{f}}$ mentioned in step 4 . We use these weights to guide the probability of selection during the bootstrapping process (following the methods described in Husak et al., 2013) from the observed MAM precipitation over the EA domain during the hindcast years (1993-2012). The years with higher weights get selected more often than other years because the frequency of selection is proportionate to the weights. We first perform this bootstrapping process for the first decad of MAM, comprised of 10 daily values of precipitation and temperature maximum and minimum. In order to build the scenarios for the first decad of the MAM season for any target year, we sampled the first decad of the MAM season from all years (1993-2012, except the target year) as described previously.

6. We then repeat this process for subsequent decads of the MAM season. For example, Fig. 4 shows the frequency of years in the available record (1993-2012) picked in generating 100 climate scenarios for the MAM season of the year 2011, which was a drought year. Based on our estimates, year 2011 was most similar to the years 2009, 1999, and 2000, which were all drought years. Beyond the MAM season our bootstrapping selection is based on the equiprobable weights (similar to climatological forecasts).

For generating seasonal hydrologic forecasts (Sect. 2.4) we only use 30 of those climate scenarios. Although all 30 scenarios aggregated over the MAM season are similar for any given target year, the bootstrapping process described above allows for uncertainties in the evolution of daily weather patterns for each scenario.

\subsection{Seasonal hydrologic forecasts}

Two sets of hindcast SM forecasts were generated by combining the antecedent conditions, one on 5 March and one on 5 April (1993-2012), with a suite of climate scenarios (daily precipitation, maximum and minimum temperature, as described in Sect. 2.3b) for the remainder of the season. (Note that the same climate scenarios were used in both cases.) We chose these dates because 5 March is near the SOS (start of season) and about a week before FEWS NET's seasonal forecast review meeting in March; likewise, 5 April is near the

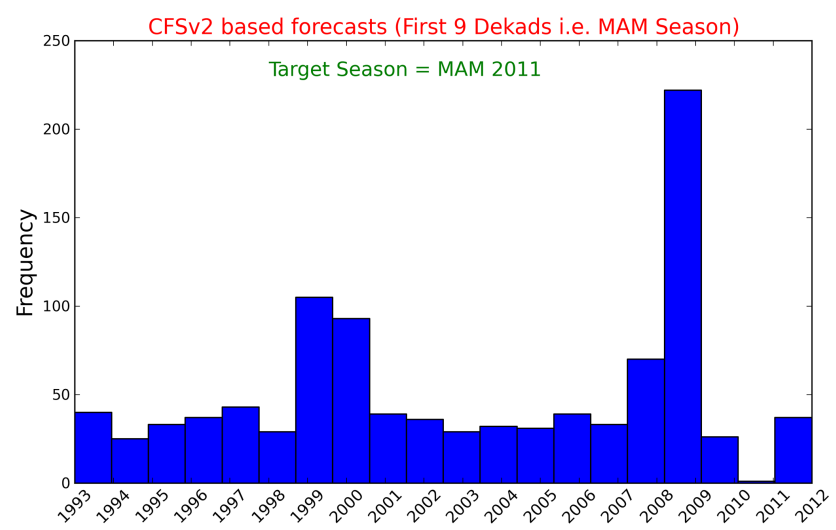

Figure 4. Frequency of picking each climatological year for generating climate scenarios (conditioned to CFSv2 based weighted probabilities) for the MAM season of the year 2011.

MOS (middle of season) and about a week before the seasonal forecast review meeting in April.

For comparison, we also generated two more sets of forecasts using the Ensemble Streamflow Prediction (ESP) method (Shukla and Lettenmaier, 2011; Wood and Lettenmaier, 2008; Wood et al., 2002). In this method, seasonal hydrologic forecasts are generated by driving the hydrologic model with atmospheric forcings sampled from the climatology. It is assumed that the climate during the upcoming season has an equal likelihood of being similar to any of the years during the climatological period (1993-2012 in this case). The forecasts are initialized using "true" initial hydrologic conditions (IHCs), so the source of hydrologic forecast skill is only the IHCs. We used the SM forecast generated using the ESP method as a baseline to compare the similar forecasts generated using CFSv2-based seasonal climate scenarios (Sect. 2.3). This comparison was done in order to examine the value of CFSv2-based climate scenarios in hydrologic forecasting, since both methods share the IHCs but differ in the climate scenarios.

\section{Evaluation of VIC-derived soil moisture for agricultural drought assessment}

First we evaluated the suitability of VIC-derived SM (generated by forcing the VIC model with high-quality observed forcings; Sect. 2.2) for providing agricultural drought assessments across our domain (Fig. 1). Hereafter we refer to this data set as "SM a posteriori estimates". We did so by comparing SM a posteriori estimates, spatially aggregated over the crop zones only, with the water requirement satisfaction index (WRSI) (Verdin and Klaver, 2002). WRSI is a water balance model that is used by Food and Agricultural Organization (FAO) as well as FEWS NET scientists to provide crop yield assessments (Senay and Verdin, 2003; Verdin and Klaver, 2002; Verdin et al., 2005); therefore, we used WRSI 


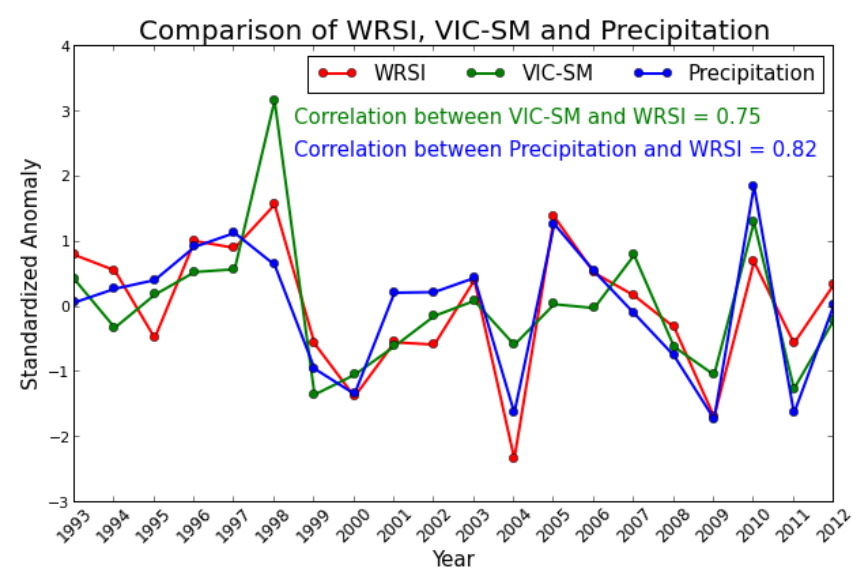

Figure 5. Comparison of MAM precipitation, SM a posteriori estimates (VIC-SM) and end-of-season (EOS) WRSI for crop zones in the focus domain for each year between 1993 and 2012.

in lieu of actual crop yield data, which is generally scarce for this region. WRSI was calculated using the same precipitation data (i.e., CHIRPS) as VIC's SM. WRSI is approximately equal to the percent of potential evapotranspiration met by available water resources, either rainfall or SM. As such, WRSI values range from 0 to 100 , with a value below 50 commonly being associated with crop failure. Because only a limited amount of excess water is retained for the next time interval in the WRSI model, the relationship of seasonal precipitation with WRSI is not entirely linear. For example, WRSI values may be the same for $100 \%$ of normal precipitation and $120 \%$ of normal precipitation, since both precipitation values meet the required available moisture for crop growth. For this reason we compared standardized anomalies of SM, rainfall and WRSI over the crop zones. As shown in Fig. 5, the Spearman rank correlation between rainfall and WRSI is 0.83 and the correlation between SM and WRSI is slightly less (0.75). We chose the Spearman rank correlation value to make sure that the correlation value is not sensitive to a few outlier years, given the small sample size. Based on this finding we postulate that VIC derived SM is a reasonable indicator of agricultural drought in the focus domain.

Next, we compared SM a posteriori estimates with the European Space Agency (ESA) Essential Climate Variable (ECV) SM data set. This data set is one of the most complete and long-term global SM data sets based on active and passive microwave remote sensing. Further details about this data set can be found in Liu et al. $(2011,2012)$. For the comparison between both data sets we calculated the standardized anomaly (anomaly divided by the standard deviation) using the climatology of 1993-2012. In Fig. 6 we present the comparison of both data sets for two above normal MAM SM years (1998 and 2010) and two below normal SM years (2000 and 2011). Although the intensity of SM anomalies

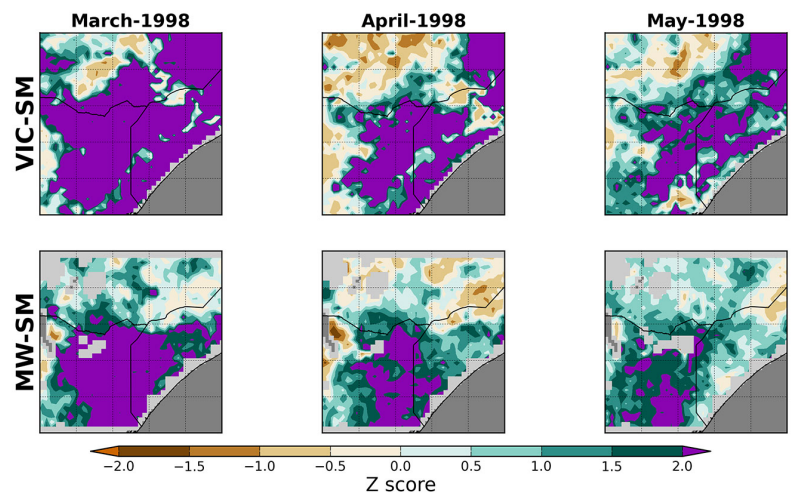

(a)
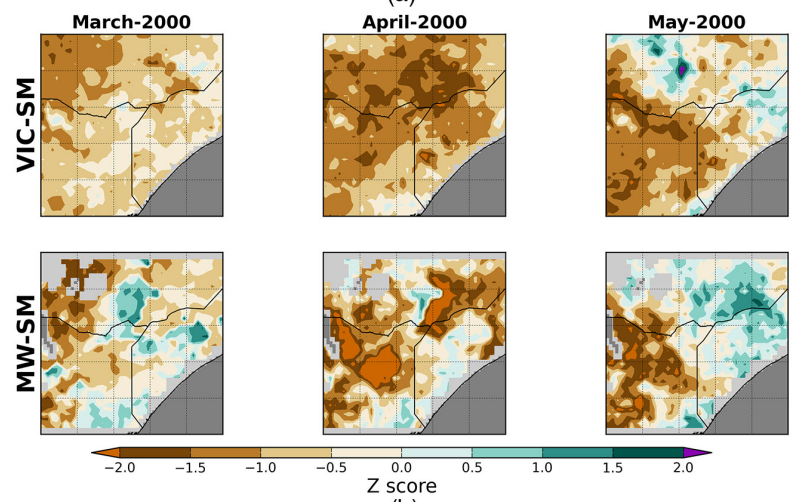

(b)
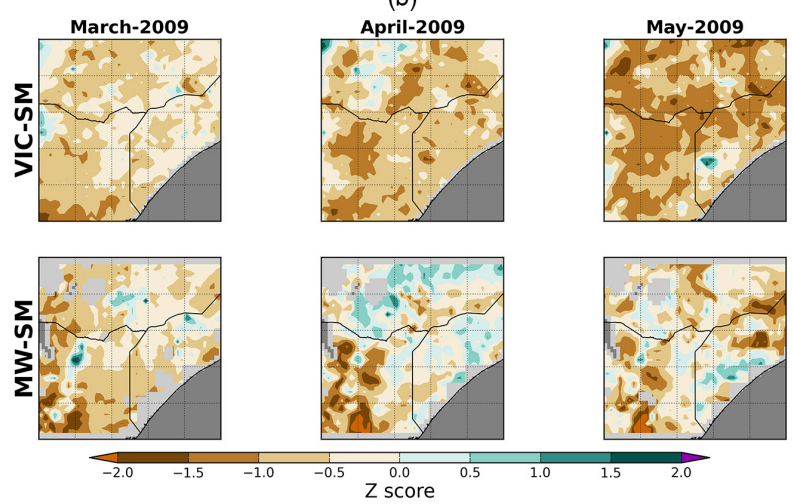

(c)
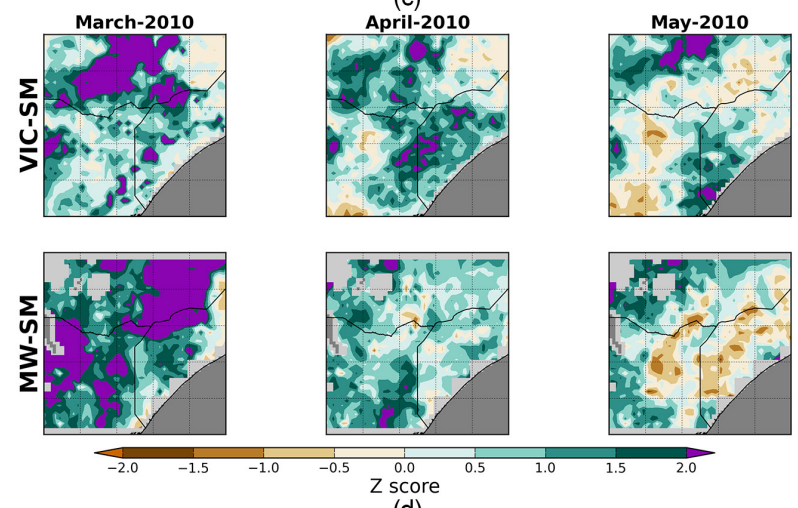

(d)

Figure 6. Comparison of standardized anomaly SM a posteriori estimates (VIC SM, sum of moisture in top two layers) and ECV microwave soil moisture (MW SM) for the March-May season of the years (a) 1998, (b) 2000, (c) 2009 and (d) 2010. 
are different between both data sets (which partly could be attributed to VIC SM being from a much deeper soil profile than the ECV SM data set), overall both data sets do agree on the general direction of the anomaly, meaning that, according to both data sets, 1998 and 2010 were wet years and 2000 and 2011 were drought years. We observed similar agreement between both data sets in other years as well (not shown here).

\section{Evaluation of precipitation and soil moisture forecasts}

Next, we assessed the skill of the precipitation and SM forecasts. Our model hindcasts consisted of an ensemble of 30 precipitation and SM scenarios for each year in the 19932012 period. We used the ensemble median of the scenarios and correlated this with the observed seasonal outcome. We used the CHIRPS to assess the skill of the precipitation forecasts and SM a posteriori estimates to assess the skill of the SM forecasts. We did so due to the lack of long-term SM observations for the region.

We compared the spatially aggregated (over the focus domain) MAM seasonal precipitation forecasts made during the 1993-2012 period and observations (CHIRPS) (Fig. 7). The value of Spearman's rank correlation between precipitation forecasts and observations is 0.67 .

Figure 8a shows the skill of SM forecasts initialized on 5 March (SOS) for a lead time of 1-3 months. (Where lead 1 is the month of March and lead 3 is the month of May.) The skill is defined as the Spearman rank correlation between the ensemble median of all 30 SM scenarios for each year and SM a posteriori estimates (Sect. 2.2). The SM forecast skill is generally greater than 0.5 across the most of the region and greater than 0.9 for some parts at the 1-month lead. The SM forecast skill dissipates as the time between forecast month and day of forecast initialization increases. This finding about the SM forecast skill is consistent with the results of other studies (Mo et al., 2012; Shukla and Lettenmaier, 2011; Shukla et al., 2013). Nevertheless, over part of the focus domain (southeastern parts of Ethiopia, eastern parts of Kenya, as well as southern Somalia) the SM forecast skill remains as high as 0.5 for up to a three-month lead time. This observation is particularly important in an early warning context, since it implies that over those regions skillful assumptions about the agricultural drought can be made early in the growing season. This lead time is particularly helpful for FEWS NET food analysts, who can provide advanced warnings about potential growing conditions in those regions.

Figure $8 \mathrm{~b}$ shows the SM forecast skill generated using the ESP method. As previously noted, the ESP method does not derive its skill from the climate forecasts and is solely based on the knowledge of the IHCs (Shukla and Lettenmaier, 2011); therefore, the comparison between Fig. 8a and $b$ shows the value of using skillful climate scenarios in improving SM forecast skill. This value is especially high-

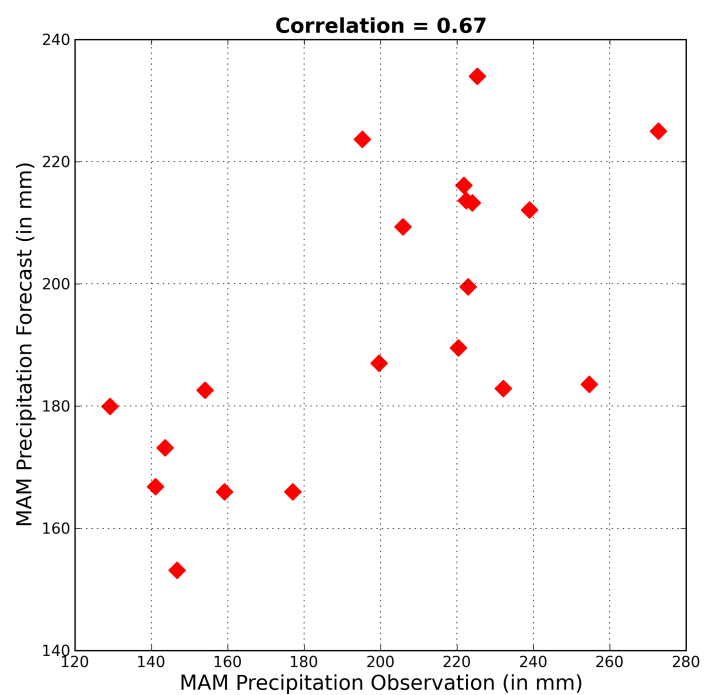

Figure 7. Comparison of ensemble median MAM precipitation forecasts and observations (CHIRPS) spatially aggregated over the focus domain.

lighted at leads of 2-3 months (when the influence of the IHCs has diminished), when Fig. 8a shows a higher level of skill than Fig. 8b.

We also calculated the SM forecast skill derived using CFSv2-based climate scenarios and the ESP method but during the forecast period starting on 5 April (Fig. 9a, b, respectively). Although SM forecast skill dissipates as one moves further from the initial state, one noteworthy observation from this figure is the higher SM forecast skill over the second and third month (lead-1 and lead-2 months, respectively) of the MAM season. Comparing lead-2 and lead-3 forecasts skill in Fig. 8a with lead-1 and lead-2 forecast skill in Fig. 9a, we see the higher values across the region in Fig. 9a, corresponding to improved EOS (end of season) information at the beginning of April compared to March. Ideally, forecasts of agricultural drought are early in the season; however, midseason is the time when the antecedent SM state has a larger influence over SM until the end of season. Such midseason outlooks still lead actual harvest dates by several months, and can therefore provide critical early warnings. This also highlights the value of incorporating precipitation during the early part of the season, which is reflected in the initial hydrologic state of the MOS. What this means, in practical terms, is that in case of a delayed onset of rainfall and/or below normal rainfall during the first month of the season, SM in the middle of the season will be below normal and the chances of recovery from the SM deficit (or failure of the crop) become lower (higher) than what they were at the beginning of the season. Again, a comparison of Fig. 9a with Fig. 9b indicates that climate scenarios add to the SM forecast skill beyond the ESP method. 


\section{Forecast initialized on March 05}

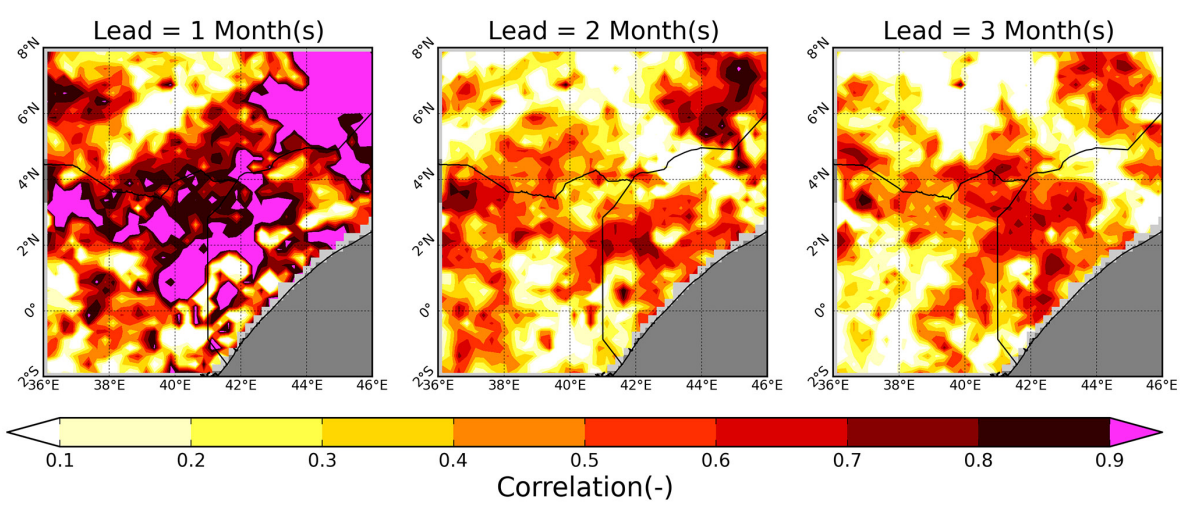

(a)

Forecast initialized on March 05

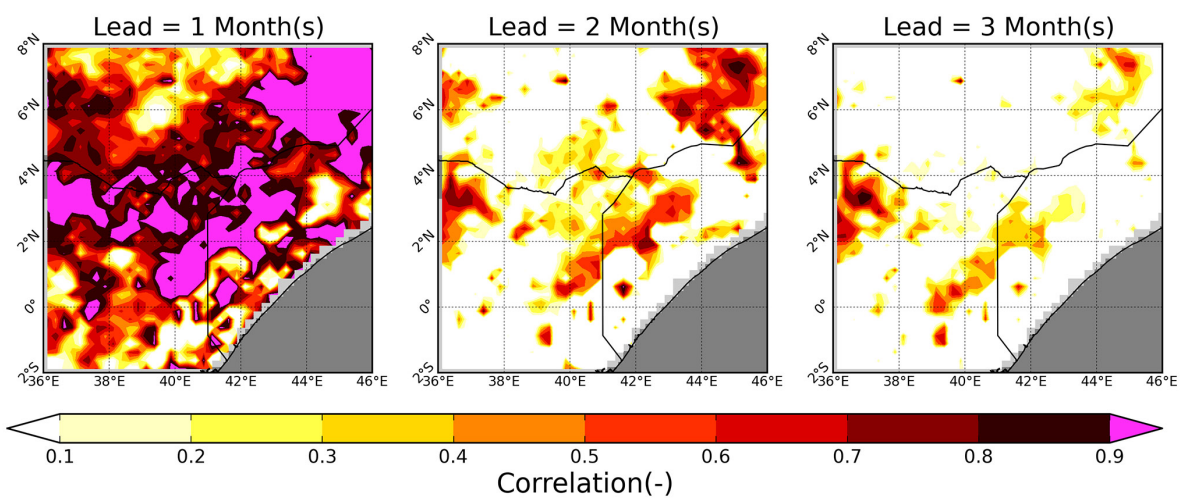

(b)

Figure 8. Skill of soil moisture forecasts (i.e., correlation between ensemble median of soil moisture forecasts and a posteriori estimates) initialized on 4 March (start of the season) estimated using (a) CFSv2-based seasonal climate scenarios and (b) ESP method.

Although Figs. 8 and 9 show that SM forecasts generated using CFSv2-based climate scenarios are skillful, one obvious question is how this system would have performed during the 2011 MAM season, which was one of the worst drought events in the history of this region. To answer this question, in Fig. 10 we compared the standardized anomaly of SM forecasts (generated by using CFSv2based climate scenarios) initialized on 5 March (top panel) and 5 April (middle panel) with SM a posteriori estimates (bottom panel). From this figure (Fig. 10) it appears that although this system would have successfully predicted 2011 as a drought year as early as 5 March, it would have underestimated the drought's severity. Forecasts made on 5 April do show elevated drought severity, though, because they used updated (drier than normal) IHCs.

Finally, we examine how the SM forecast skill varies among other drought years vs. normal years by estimating the spatial pattern correlation between SM forecasts (generated using CFSv2-based seasonal climate scenarios) and SM a posteriori estimates over the region (Fig. 11). The higher the correlation, the better the forecast is in capturing the spa- tial variability of SM anomaly patterns. Spatial anomaly pattern correlation is greater than 0.60 for all years (Fig. 10). As indicated in Fig. 10, there is a correlation of -0.62 between the spatial anomaly pattern correlation for MAM SM and standardized anomaly of MAM precipitation, which means that spatial anomaly pattern correlation is generally higher (lower) for a negative (positive) anomaly of precipitation. In almost all years (except one) the value of spatial anomaly pattern correlation is greater than 0.8 when the MAM precipitation anomaly was negative (i.e., meteorological drought years). This finding indicates that, in terms of capturing spatial variability of SM, this system does relatively better during drought years than in normal or above normal years.

\section{Concluding remarks}

Our primary findings are as follows:

1. The VIC-model-derived SM values over the crop zones of the focus domain aligns well with end-of-season WRSI, the FAO indicator that is often used for providing crop yield assessments. 


\section{Forecast initialized on April 05}
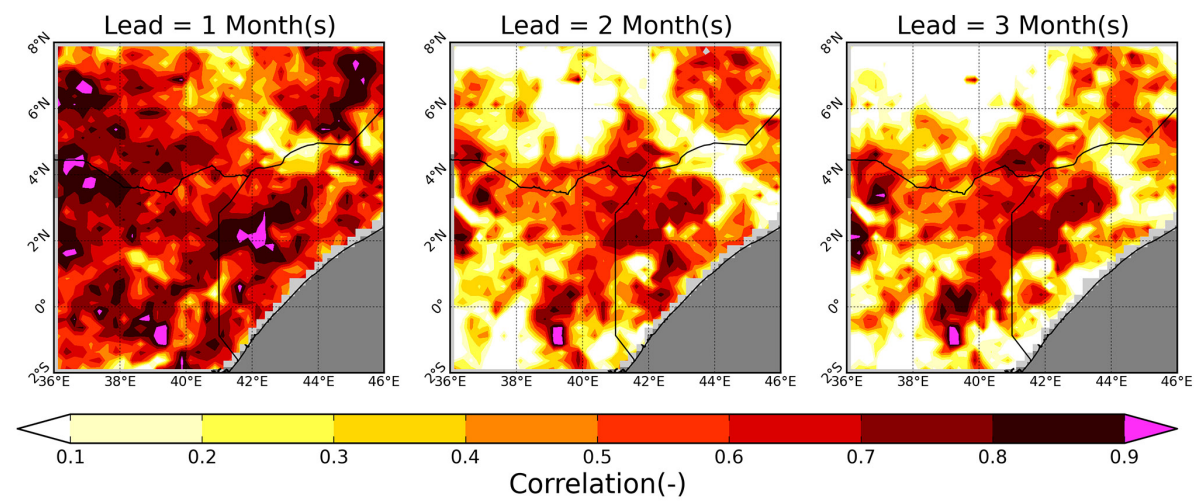

(a)

\section{Forecast initialized on April 05}

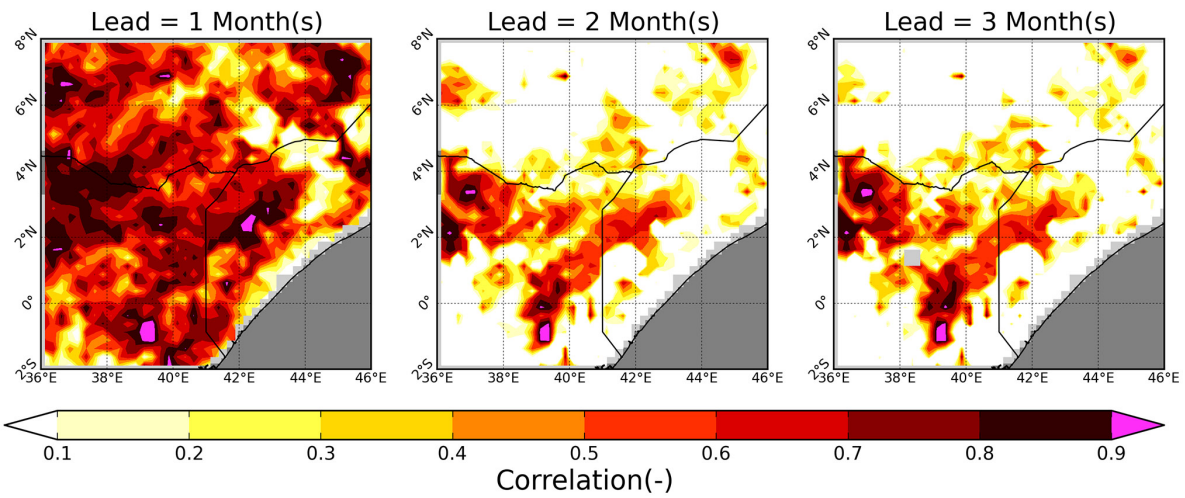

(b)

Figure 9. Same as in Fig. 8 but for forecasts initialized on 5 April (middle of season).

2. The hybrid approach that utilizes dynamical CFSv2 precipitation forecasts over EA and the Indo-Pacific ocean to statistically forecast rainfall over the focus domain is more skillful (correlation $=0.67$ for MAM precipitation forecasts initialized in February) than using climatology (ESP) alone.

3. Forecasts initialized midseason make the greatest contribution to end-of-season SM forecast skill. SM forecasts initialized at the beginning of the season were skillful across the domain at 1-month lead, while the forecast skill during the second and third months of the season increased when the SM forecast was initialized with an updated initial hydrologic state, even with the same climate scenarios used at the time of the start of the season.

4. The spatial anomaly pattern correlation between SM forecasts and SM a posteriori estimates are generally higher ( $>0.8$ ) for drought years, indicating the value of this system during drought events, which is the primary focus of FEWS NET.
We described the development and implementation of a seasonal hydrologic forecast system that is being used by FEWS NET scientists to provide seasonal assessment of agricultural production for food-insecure regions of EA. This is certainly not the first attempt to provide seasonal hydrologic forecasts for EA. Our approach is most similar to that of Yuan et al. (2013a) and to the Sheffield et al. (2014) Africa Flood and Drought Monitor as mentioned in Sect. 2. Specifically, we used the same model parameters and temperature and wind forcings. The main differences between our system and theirs are the high-resolution, station-intensive, bias-corrected CHIRPS precipitation forcings and the hybrid statistical-dynamical approach used for generating seasonal climate scenarios.

Besides the Africa Flood and Drought Monitor, other approaches have been developed for drought monitoring and forecasting for Africa and EA. Rojas et al. (2011) described a drought monitoring approach that utilizes the vegetation health index (VHI) from the Advanced Very High Resolution Radiometer (AVHRR) averaged over the crop season. Anderson et al. (2012) suggested an approach that takes advantage of the relative strength of three different methods for 


\section{Comparison of SM forecast and SM a posteriori estimates for 2011 MAM Season}
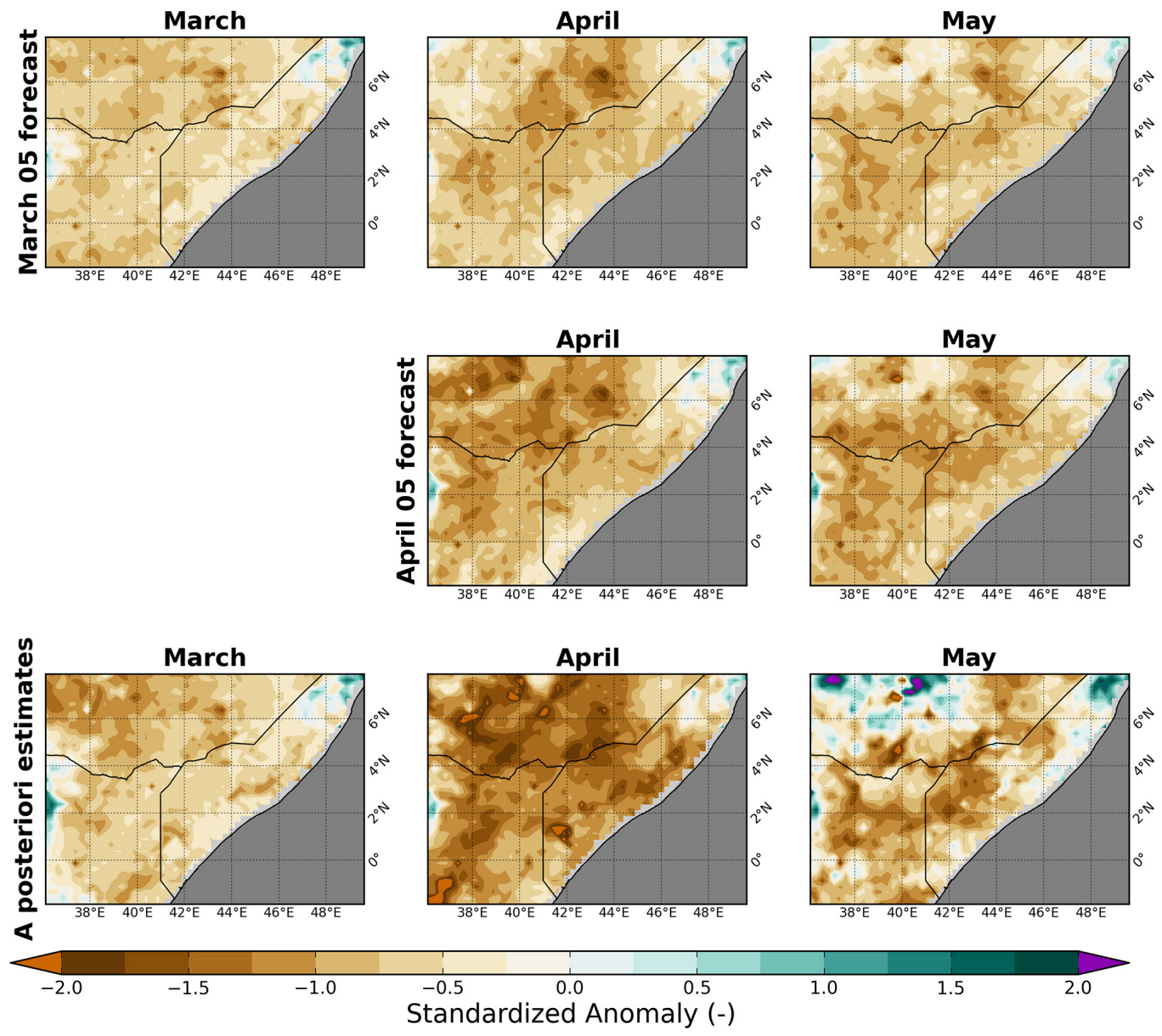

Figure 10. Comparison of standardized anomaly of SM forecast generated using CFSv2-based seasonal climate scenarios with SM a posteriori estimates during the MAM season of the year 2011. Top panels show March-May forecasts generated on 5 March, middle panels show the same for April and May generated on 5 April and bottom panels show the SM a posteriori estimates.

obtaining SM estimates. Mwangi et al. (2014) examined the skill of standardized precipitation index (SPI) forecasts based on European Centre for Medium-Range Weather Forecasts (ECMWF) and found that for the MAM season the skill was generally below 0.4 for forecasts issued in February. Meroni et al. (2014) described an approach to provide early warning of unfavorable crop and pasture conditions using a statistical analysis of early observation data. While these approaches are valuable contributions, it is important for FEWS NET to have an in-house platform to help provide seasonal assessment of agricultural drought conditions and meet the decision-making needs of the food analysts. This also allows us to test different approaches to generate climate scenarios and estimate the initial hydrologic state (approaches that we plan to implement in this system are described in further detail in the next section).

\section{Future directions}

As mentioned before, this seasonal agricultural drought forecast system is already being used to provide scientific assessment of seasonal agricultural outlook. However, we acknowledge that further improvements to this system will better meet the decision-making needs of the food analysts. Next, we describe the three primary avenues for improvements in this system.

\subsection{Improvement in the estimation of initial hydrologic state}

Differences in the way that hydrologic models partition precipitation into evapotranspiration and runoff, and their different water holding capacity, lead to differences in SM sensitivity to precipitation variability. These differences may lead to discrepancies among the model-based SM drought estimates (Crow et al., 2012; Wang et al., 2009). Therefore, we 


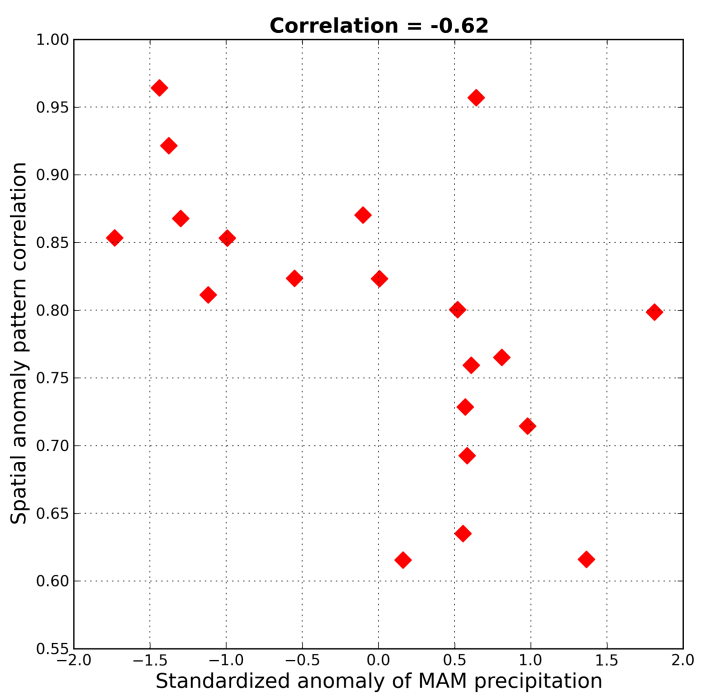

Figure 11. Comparison between spatial anomaly pattern correlation (between MAM mean soil moisture forecast initialized at the start of season and observation) and standardized anomaly of MAM precipitation. This plot indicates that spatial anomaly pattern correlation is generally higher $(>0.8)$ during drought years (when standardized anomaly of MAM precipitation is $<0$ ).

are transferring this agricultural drought forecast system to NASA's FEWS NET Land Data Assimilation System, an instance of NASA's Land Information System (LIS) (Kumar et al., 2006) that includes hydrologic and soil water balance models such as Noah (Ek et al., 2003; Schaake et al., 1996) and WRSI (Verdin and Klaver, 2002; Verdin et al., 2005) in addition to VIC and will include other land surface models such as the Catchment model (Koster et al., 2000) in the near future.

Besides using a multimodel framework for seasonal agricultural drought forecasting, another promising approach that we plan to test is data assimilation. Previous works have shown that data assimilation improves estimates of SM and snow state in large-scale hydrologic models (Andreadis and Lettenmaier, 2006; Kumar et al., 2008), leading to a higher hydrologic forecast skill. Therefore, we will test if assimilating satellite-based SM estimates (for top soil layer) and/or total water storage (as estimated by NASA's Gravity Recovery and Climate Experiment) improves our SM forecasts skill. Satellite observations of vegetation can also provide useful information about crop performance (Meroni et al., 2014; Funk et al., 2008), and we will assess the potential assimilation of this information as well.

\subsection{Improvement in climate scenario building process}

For the current version of the seasonal agricultural drought forecast system we only use dynamical seasonal climate forecasts from CFSv2. However, NCEP's National Multi-Model Ensemble system (NMME;
http://www.cpc.ncep.noaa.gov/products/NMME/) includes five other models aside from CFSv2. Recent studies have demonstrated the value of using multimodel ensembles of seasonal forecasts relative to using just one of the models (Hagedorn et al., 2005; Kirtman et al., 2014; Lavers et al., 2009; Yuan and Wood, 2013). Therefore, we plan to use NMME model ensembles to generate climate scenarios.

We also aim to test other statistical forecasting methods to improve the skill of climate scenarios. One of those methods was recently suggested by Nicholson (2014), who found that atmospheric variables, when used as predictors, can provide a higher rainfall forecast skill in the Greater Horn of Africa than other surface variables such as SST and sea level pressure (SLP).

\subsection{Improvement in presentation of the forecasts}

The primary goal of this seasonal agricultural drought forecast system is to assist FEWS NET's food analysts with their decision-making process. Hence, it is imperative for us to provide forecasts in a manner that is easily understandable by the decision-makers and still includes key information about the forecast (such as probabilities of a region being either wet or dry in an upcoming season). We recognize that this is a slow and iterative process; however, through this unique position of working directly with the food analysts we have the perfect opportunity to translate science into action. We plan to improve the presentation of our forecasts by incorporating the feedback of the end users (FEWS NET's food analysts) into our forecasts. Thus far, we have learned that providing the forecasts in terms of the chances of drought onset/persistence/recovery and best analogs is well-received.

Acknowledgements. This research was supported by the Postdocs Applying Climate Expertise (PACE) fellowship program, partially funded by the NOAA Climate Program Office and administered by the UCAR Visiting Scientist Programs. Additional support for this work was provided by the USAID's FEWS NET (USGS award \#G09AC00001), NOAA Technical Transitions grant NA11OAR4310151 and NASA SERVIR grant NNH12ZDA001N. The authors would like to thank Diego Pedreros (USGS/UCSB) for his work on generating WRSI data.

Finally, we also like to extend our thanks to Justin Sheffield, Nate Chaney, and others at Terrestrial Hydrology Research Group in the Department of Civil and Environmental Engineering at Princeton University for their work on developing forcing and model parameter data sets and kindly sharing them with us.

Edited by: M. Werner 


\section{References}

Adam, J. C., Haddeland, I., Su, F., and Lettenmaier, D. P.: Simulation of reservoir influences on annual and seasonal streamflow changes for the Lena, Yenisei, and Ob' rivers, J. Geophys. Res., 112, D24114, doi:10.1029/2007JD008525, 2007.

Anderson, W. B., Zaitchik, B. F., Hain, C. R., Anderson, M. C., Yilmaz, M. T., Mecikalski, J., and Schultz, L.: Towards an integrated soil moisture drought monitor for East Africa, Hydrol. Earth Syst. Sci., 16, 2893-2913, doi:10.5194/hess-16-28932012, 2012.

Andreadis, K. M. and Lettenmaier, D. P.: Assimilating remotely sensed snow observations into a macroscale hydrology model, Adv. Water Resour., 29, 872-886, 2006.

Batjes, N. H.: A world dataset of derived soil properties by FAOUNESCO soil unit for global modelling, Soil Use Manage., 13, 9-16, 1997.

Chaney, N., Sheffield, J., Villarini, G., and Wood, E. F.: Spatial analysis of trends in climatic extremes with a high resolution gridded daily meteorological data set over Sub-Saharan Africa, J. Climate, 27, 5815-5835, doi:10.1175/JCLI-D-13-00423.1, 2014.

Checchi, F. and Robinson, W. C.: Mortality among populations of southern and central Somalia affected by severe food insecurity and famine during 2010-2012, FAO/FSNAU and FEWSNET, available from: http://www.fsnau.org/in-focus/study-report, last accessed: 23 September 2014, 2013.

Cosby, B. J., Hornberger, G. M., Clapp, R. B., and Ginn, T. R.: A statistical exploration of the relationships of soil moisture characteristics to the physical properties of soils, Water Resour. Res., 20, 682-690, 1984.

Crow, W. T., Kumar, S. V., and Bolten, J. D.: On the utility of land surface models for agricultural drought monitoring, Hydrol. Earth Syst. Sci., 16, 3451-3460, doi:10.5194/hess-16-34512012, 2012.

Ek, M. B., Mitchell, K. E., Lin, Y., Rogers, E., Grunmann, P., Koren, V., Gayno, G., and Tarpley, J. D.: Implementation of Noah land surface model advances in the National Centers for Environmental Prediction operational mesoscale Eta model, J. Geophys. Res.-Atmos., 108, 8851, doi:10.1029/2002JD003296, 2003.

Funk, C., Senay, G., Asfaw, A., Verdin, J., Rowland, J., Michaelson, J., Eilerts, G., Korecha, D., and Choularton, R.: Recent drought tendencies in Ethiopia and equatorial-subtropical eastern Africa, Famine Early Warning System Network, USAID, Washington, D.C., 2005.

Funk, C., Dettinger, M. D., Michaelsen, J. C., Verdin, J. P., Brown, M. E., Barlow, M., and Hoell, A.: Warming of the Indian Ocean threatens eastern and southern African food security but could be mitigated by agricultural development, P. Natl. Acad. Sci. USA, 105, 11081-11086, doi:10.1073/pnas.0708196105, 2008.

Funk, C., Eilerts, G., Davenport, F., and Michaelsen, J.: A Climate Trend Analysis of Kenya - August 2010, USGS fact sheet, USGS, Sioux Falls, USA, 2010

Funk, C., Husak, G., Michaelsen, J., Shukla, S., Hoell, A., Lyon, B., Hoerling, M. P., Liebmann, B., Zhang, T., Verdin, J., Galu, G., Eilerts, G., and Rowland, J.: Attribution of 2012 and 2003-12 rainfall deficits in eastern Kenya and southern Somalia, B. Am. Meteorol. Soc., 95, S45-S48, 2013.
Funk, C., Hoell, A., Shukla, S., Bladé, I., Liebmann, B., Roberts, J. B., Robertson, F. R., and Husak, G.: Predicting East African spring droughts using Pacific and Indian Ocean sea surface temperature indices, Hydrol. Earth Syst. Sci. Discuss., 11, 31113136, doi:10.5194/hessd-11-3111-2014, 2014.

Funk, C., Peterson, P., Landsfield, M., Pedreros, D., Verdin, J., Rowland, J., Romero, B., Husak, G., Michaelsen, J., and Vedin, A.: A Quasi-global Precipitation Time Series for Drought Monitoring, USGS, EROS Data Center, available at: http://pubs.usgs.gov/ds/ 832/pdf/ds832.pdf (last access: 23 September 2014), 2014b.

Hagedorn, R., Doblas-Reyes, F. J., and Palmer, T. N.: The rationale behind the success of multi-model ensembles in seasonal forecasting - I. Basic concept, Tellus A, 57, 219-233, doi:10.1111/j.1600-0870.2005.00103.x, 2005.

Hamill, T. M., Bates, G. T., Whitaker, J. S., Murray, D. R., Fiorino, M., Galarneau, T. J., Zhu, Y., and Lapenta, W.: NOAA's Second-Generation Global Medium-Range Ensemble Reforecast Dataset, B. Am. Meteorol. Soc., 94, 1553-1565, doi:10.1175/BAMS-D-12-00014.1, 2013.

Hidalgo, H. G., Dettinger, M. D., and Cayan, D. R.: Downscaling with constructed analogues: Daily precipitation and temperature fields over the United States, California Energy Commission PIER Final Project Report CEC-500-2007-123, Sacramento, CA, 2008.

Hillier, D.: A dangerous delay: the cost of late response to early warnings in the 2011 drought in the Horn of Africa, Oxfam, available from: http://books.google.com/books? $\mathrm{hl}=\mathrm{en} \backslash \& \mathrm{lr}=\mid \& \mathrm{id}=3 \mathrm{c} 5 \mathrm{o} 5 \mathrm{gnSj} 74 \mathrm{C} \backslash \& \mathrm{oi}=$ fnd $\backslash \& \mathrm{pg}=\mathrm{PA} 3 \backslash \& \mathrm{dq}=$ Drought $\% 2 \mathrm{BFamine} \% 2 \mathrm{BEast}+$ Africal\&ots=Fdonfsy2jh $\backslash \&$ sig= pHT4RdBcOydIBikstX0X17sb0sQ (last access: 26 June 2013), 2012.

Hoell, A. and Funk, C.: Indo-Pacific sea surface temperature influences on failed consecutive rainy seasons over eastern Africa, Clim. Dynam., 43, 1645-1660, doi:10.1007/s00382-013-1991-6, 2013a.

Hoell, A. and Funk, C.: The ENSO-related West Pacific Sea Surface Temperature Gradient, J. Climate, 26, 9545-9562, doi:10.1175/JCLI-D-12-00344.1, 2013b.

Husak, G. J., Funk, C. C., Michaelsen, J., Magadzire, T., and Goldsberry, K. P.: Developing seasonal rainfall scenarios for food security early warning, Theor. Appl. Climatol., 114, 291-302, doi:10.1007/s00704-013-0838-8, 2013.

Keyantash, J. and Dracup, J. A.: The quantification of drought: An evaluation of drought indices, B. Am. Meteorol. Soc., 83, 11671180, 2002.

Kirtman, B. P., Min, D., Infanti, J. M., Kinter III, J. L., Paolino, D. A., Zhang, Q., van den Dool, H., Saha, S., Mendez, M. P., and Becker, E.: The North American Multi-Model Ensemble (NMME): Phase-1 Seasonal to Interannual Prediction, Phase-2 Toward Developing Intra-Seasonal Prediction, B. Am. Meteorol. Soc., 95, 585-601, doi:10.1175/BAMS-D-12-00050.1, 2014.

Koster, R. D., Suarez, M. J., Ducharne, A., Stieglitz, M. and Kumar, P.: A catchment-based approach to modeling land surface processes in a general circulation model: 1. Model structure, J. Geophys. Res.-Atmos., 105, 24809-24822, doi:10.1029/2000JD900327, 2000. 
Koster, R. D., Mahanama, S. P. ., Livneh, B., Lettenmaier, D. P., and Reichle, R. H.: Skill in streamflow forecasts derived from large-scale estimates of soil moisture and snow, Nat. Geosci., 3, 613-616, 2010.

Kumar, S., Peterslidard, C., Tian, Y., Houser, P., Geiger, J., Olden, S., Lighty, L., Eastman, J., Doty, B., and Dirmeyer, P.: Land information system: An interoperable framework for high resolution land surface modeling, Environ. Modell. Softw., 21, 14021415, doi:10.1016/j.envsoft.2005.07.004, 2006.

Kumar, S. V., Reichle, R. H., Peters-Lidard, C. D., Koster, R. D., Zhan, X., Crow, W. T., Eylander, J. B., and Houser, P. R.: A land surface data assimilation framework using the land information system: Description and applications, Adv. Water Resour., 31, 1419-1432, doi:10.1016/j.advwatres.2008.01.013 2008.

Lavers, D., Luo, L., and Wood, E. F.: A multiple model assessment of seasonal climate forecast skill for applications, Geophys. Res. Lett., 36, L23711, doi:10.1029/2009GL041365, 2009.

Liang, X., Lettenmaier, D. P., Wood, E. F., and Burges, S. J.: A simple hydrologically based model of land surface water and energy fluxes for general circulation models, J. Geophys. Res.-Atmos., 99, 14415-14428, 1994

Liang, X., Wood, E. F., and Lettenmaier, D. P.: Surface soil moisture parameterization of the VIC-2L model: Evaluation and modification, Global Planet. Change, 13, 195-206, 1996.

Liu, Y. Y., Parinussa, R. M., Dorigo, W. A., De Jeu, R. A. M., Wagner, W., van Dijk, A. I. J. M., McCabe, M. F., and Evans, J. P.: Developing an improved soil moisture dataset by blending passive and active microwave satellite-based retrievals, Hydrol. Earth Syst. Sci., 15, 425-436, doi:10.5194/hess-15-425-2011, 2011.

Liu, Y. Y., Dorigo, W. A., Parinussa, R. M., de Jeu, R. A. M., Wagner, W., McCabe, M. F., Evans, J. P., and van Dijk, A. I. J. M.: Trend-preserving blending of passive and active microwave soil moisture retrievals, Remote Sens. Environ., 123, 280-297, doi:10.1016/j.rse.2012.03.014, 2012.

Livneh, B., Rosenberg, E. A., Lin, C., Nijssen, B., Mishra, V., Andreadis, K. M., Maurer, E. P., and Lettenmaier, D. P.: A LongTerm Hydrologically Based Dataset of Land Surface Fluxes and States for the Conterminous United States: Update and Extensions, J. Climate, 26, 9384-9392, doi:10.1175/JCLI-D-1200508.1, 2013.

Lyon, B. and DeWitt, D. G.: A recent and abrupt decline in the East African long rains, Geophys. Res. Lett., 39, L02702, doi:10.1029/2011GL050337, 2012.

Maurer, E. P., Wood, A. W., Adam, J. C., Lettenmaier, D. P., and Nijssen, B.: A Long-Term Hydrologically Based Dataset of Land Surface Fluxes and States for the Conterminous United States, J. Climate, 15, 3237-3251, 2002.

Meroni, M., Fasbender, D., Kayitakire, F., Pini, G., Rembold, F., Urbano, F., and Verstraete, M. M.: Early detection of biomass production deficit hot-spots in semi-arid environment using FAPAR time series and a probabilistic approach, Remote Sens. Environ., 142, 57-68, doi:10.1016/j.rse.2013.11.012, 2014.

Mo, K. C., Shukla, S., Lettenmaier, D. P. and Chen, L.-C.: Do Climate Forecast System (CFSv2) forecasts improve seasonal soil moisture prediction?, Geophys. Res. Lett., 39, L23703, doi:10.1029/2012GL053598, 2012.

Mosley, J.: Translating Famine Early Warning into Early Action: An East Africa Case Study, available from: http://www.chathamhouse.org/sites/default/files/public/
Research/Africa/1112pp_mosley.pdf (last access: 26 June 2013), 2012.

Mwangi, E., Wetterhall, F., Dutra, E., Di Giuseppe, F., and Pappenberger, F.: Forecasting droughts in East Africa, Hydrol. Earth Syst. Sci., 18, 611-620, doi:10.5194/hess-18-611-2014, 2014.

Myneni, R. B., Ramakrishna, R., Nemani, R., and Running, S. W.: Estimation of global leaf area index and absorbed PAR using radiative transfer models, IEEE T. Geosci. Remote Sens., 35, 1380-1393, 1997.

Nicholson, S. E.: The predictability of rainfall over the Greater Horn of Africa, Part I. Prediction of seasonal rainfall, J. Hydrometeorol., 15, 1011-1027, doi:10.1175/JHM-D-13-062.1, 2014.

Nijssen, B., Lettenmaier, D. P., Liang, X., Wetzel, S. W., and Wood, E. F.: Streamflow simulation for continental-scale river basins, Water Resour. Res., 33, 711-724, 1997.

Nijssen, B., O’Donnell, G. M., Hamlet, A. F., and Lettenmaier, D. P.: Hydrologic sensitivity of global rivers to climate change, Climatic Change, 50, 143-175, 2001a.

Nijssen, B., O'Donnell, G. M., Lettenmaier, D. P., Lohmann, D., and Wood, E. F.: Predicting the Discharge of Global Rivers, J. Climate, 14, 3307-3323, doi:10.1175/15200442(2001)014<3307:PTDOGR>2.0.CO;2, $2001 \mathrm{~b}$.

Owiti, Z., Ogallo, L. A., and Mutemi, J.: Linkages between the Indian Ocean Dipole and east African seasonal rainfall anomalies, J. Kenya Meteorol. Soc., 2, 3-17, 2008.

Pricope, N. G., Husak, G., Lopez-Carr, D., Funk, C., and Michaelsen, J.: The climate-population nexus in the East African Horn: Emerging degradation trends in rangeland and pastoral livelihood zones, Global Environ. Change, 23, 1525-1541, doi:10.1016/j.gloenvcha.2013.10.002, 2013.

Rojas, O., Vrieling, A., and Rembold, F.: Assessing drought probability for agricultural areas in Africa with coarse resolution remote sensing imagery, Remote Sens. Environ., 115, 343-352, doi:10.1016/j.rse.2010.09.006, 2011.

Schaake, J. C., Koren, V. I., Duan, Q.-Y., Mitchell, K., and Chen, F.: Simple water balance model for estimating runoff at different spatial and temporal scales, J. Geophys. Res.-Atmos., 101, 74617475, doi:10.1029/95JD02892, 1996.

Senay, G. B. and Verdin, J.: Characterization of yield reduction in Ethiopia using a GIS-based crop water balance model, Can. J. Remote Sens., 29, 687-692, 2003.

Sheffield, J., Goteti, G., and Wood, E. F.: Development of a 50-year high-resolution global dataset of meteorological forcings for land surface modeling, J. Climate, 19, 3088-3111, doi:10.1175/JCLI3790.1, 2006.

Sheffield, J., Wood, E. F., Chaney, N., Guan, K., Sadri, S., Yuan, X., Olang, L., Amni, A., Ali, A., and Demuth, S.: A Drought Monitoring and Forecasting System for Sub-Sahara African Water Resources and Food Security, B. Am. Meteorol. Soc., 95, 861-882, doi:10.1175/BAMS-D-12-00124.1, 2014.

Shukla, S. and Lettenmaier, D. P.: Seasonal hydrologic prediction in the United States: understanding the role of initial hydrologic conditions and seasonal climate forecast skill, Hydrol. Earth Syst. Sci., 15, 3529-3538, doi:10.5194/hess-15-35292011, 2011.

Shukla, S., Sheffield, J., Wood, E. F., and Lettenmaier, D. P.: On the sources of global land surface hydrologic predictability, Hydrol. Earth Syst. Sci., 17, 2781-2796, doi:10.5194/hess-17-27812013, 2013. 
Tierney, J. E., Smerdon, J. E., Anchukaitis, K. J., and Seager, R.: Multidecadal variability in East African hydroclimate controlled by the Indian Ocean, Nature, 493, 389-392, doi:10.1038/nature11785, 2013.

Todini, E.: The ARNO rainfall-runoff model, J. Hydrol., 175, 339$382,1996$.

Troy, T. J., Wood, E. F., and Sheffield, J.: An efficient calibration method for continental-scale land surface modeling, Water Resour. Res., 44, W09411, doi:10.1029/2007WR006513, 2008.

Verdin, J., Funk, C., Senay, G., and Choularton, R.: Climate science and famine early warning, Philos. T. Roy. Soc. B, 360, 2155$2168,2005$.

Verdin, J. and Klaver, R.: Grid-cell-based crop water accounting for the famine early warning system, Hydrol. Process., 16, 16171630, 2002.

Wang, A., Bohn, T. J., Mahanama, S. P., Koster, R. D., and Lettenmaier, D. P.: Multimodel ensemble reconstruction of drought over the continental United States, J. Climate, 22, 2694-2712, 2009.

Williams, A. P. and Funk, C.: A westward extension of the warm pool leads to a westward extension of the Walker circulation, drying eastern Africa, Clim. Dynam., 37, 2417-2435, doi:10.1007/s00382-010-0984-y, 2011.
Wood, A. W. and Lettenmaier, D. P.: An ensemble approach for attribution of hydrologic prediction uncertainty, Geophys. Res. Lett., 35, L14401, doi:10.1029/2008GL034648, 2008.

Wood, A. W., Maurer, E. P., Kumar, A., and Lettenmaier, D. P.: Long-range experimental hydrologic forecasting for the eastern United States, J. Geophys. Res., 107, 4429, doi:10.1029/2001JD000659, 2002.

Yuan, X. and Wood, E. F.: Multimodel seasonal forecasting of global drought onset, Geophys. Res. Lett., 40, 4900-4905, doi:10.1002/grl.50949, 2013.

Yuan, X., Wood, E. F., Chaney, N. W., Sheffield, J., Kam, J., Liang, M., and Guan, K.: Probabilistic Seasonal Forecasting of African Drought by Dynamical Models, J. Hydrometeorol., 14, 17061720, doi:10.1175/JHM-D-13-054.1, 2013a.

Yuan, X., Wood, E. F., Roundy, J. K., and Pan, M.: CFSv2Based Seasonal Hydroclimatic Forecasts over the Conterminous United States, J. Climate, 26, 4828-4847, doi:10.1175/JCLI-D12-00683.1, 2013b. 